\title{
Application of Light-emitting-diodes to Annular-type Photocatalytic Reactor for Removal of Indoor-level Benzene and Toluene
}

\author{
Wan-Kuen Jo*, Hyun-Jung Kang, Kun-Hwan Kim \\ Department of Environmental Engineering, Kyungpook National University Daegu 702-701, Korea \\ (Manuscript received 19 January, 2012; revised 21 March, 2012; accepted 19 April, 2012)
}

\begin{abstract}
Unlike water applications, the photocatalytic technique utilizing light-emitting-diodes as an alternative light source to conventional lamp has rarely been applied for low-level indoor air purification. Accordingly, this study investigated the applicability of UV-LED to annular-type photocatalytic reactor for removal of indoor-level benzene and toluene at a low concentration range associated with indoor air quality issues. The characteristics of photocatalyst was determined using an $\mathrm{X}$-ray diffraction meter and a scanning electron microscope. The photocatalyst baked at $350{ }^{\circ} \mathrm{C}$ exhibited the highest photocatalytic degradation efficiencies(PDEs) for both benzene and toluene, and the photocatalysts baked at three higher temperatures $\left(450,550\right.$, and $\left.650{ }^{\circ} \mathrm{C}\right)$ did similar PDEs for these compounds. The average PDEs over a 3-h period were $81 \%$ for benzene and close to $100 \%$ for toluene regarding the photocatalyst baked at $350{ }^{\circ} \mathrm{C}$, whereas they were 61 and $74 \%$ for benzene and toluene, respectively, regarding the photocatalyst baked at $650{ }^{\circ} \mathrm{C}$. As the light intensity increased from 2.4 to 3.5 $\mathrm{MW} \mathrm{cm} \mathrm{cm}^{-1}$, the average PDE increased from 36 to $81 \%$ and from $44 \%$ to close to $100 \%$ for benzene and toluene, respectively. In addition, as the flow rate increased from 0.1 to $0.5 \mathrm{~L} \mathrm{~min}^{-1}$, the average PDE decreased from $81 \%$ to close to zero and from close to $100 \%$ to $7 \%$ for benzene and toluene, respectively. It was found that the annular-type photocatalytic reactor inner-inserted with UV-LEDs can effectively be applied for the decomposition of low-level benzene and toluene under the operational conditions used in this study.
\end{abstract}

Key Words : Photocatalytic degradation, Light-emitting-diode, Baking temperature, Light intensity, Flow rate

\section{Introduction}

Environmental exposure to aromatic hydrocarbons, such as benzene and toluene, has received a great amount of concern because of the adverse health effects of these compounds and their prevalence in indoor as well as outdoor environments. Benzene is a known carcinogen, inducing diseases such as leukemia(IARC, 2004), and toluene is a toxic chemical causing damage to the nervous system and the liver(Revilla et al., 2007). Residences are an

*Corresponding author : Wan-Kuen Jo, Department of Environmental Engineering, Kyungpook National University, Daegu 702-701, Korea

Phone: +82-53-950-6584

E-mail: wkjo@knu.ac.kr important indoor microenvironment for potential exposure to these hazardous/toxic compounds. Benzene and toluene are two of several monocyclic aromatic hydrocarbons which are frequently detected at high concentration levels in both urban indoor and outdoor air(Ohura et al., 2009; Schlink et al., 2010). Typically, both benzene and toluene levels in urban air are higher than those of rural or suburban air(Jia et al., 2008; Pérez-Rial et al., 2010). These elevated urban atmospheric levels have been directly associated with various urban sources such as industrial discharges and the burning of fossil fuels(Roukos et al., 2009). Atmospheric benzene and toluene can penetrate indoors, thereby elevating their indoor levels(Häninen et al., 2004). Furthermore, indoor 
benzene and toluene levels have been found to be further elevated by various indoor sources, such as consumer products, cigarette smoke, and/or building materials(Jia et al., 2008). These characteristics of benzene and toluene lead to efforts to develop control means for these pollutants in order to minimize health risk from indoor air exposure.

Heterogeneous photocatalysis over titanium dioxide $\left(\mathrm{TiO}_{2}\right)$ is one of most attractive advanced oxidation processes, which has proved to be a recent, efficient tool for degrading various environmental pollutants(Choi et al., 2007; Bougheloum and Messalhi, 2009; Aïssa et al., 2011). This technology provides a number of advantages over traditional technologies such as activated carbon adsorption and thermal treatment. Whereas conventional adsorption method only transfers gaseous pollutants to another phase( $\mathrm{Lu}$ and Wey, 2007), photocatalysis has the potential to degrade a broad range of volatile organic compounds(VOCs) to $\mathrm{CO}_{2}$ and $\mathrm{H}_{2} \mathrm{O}$ as a result of reactions either with molecular oxygen or with hydroxyl radicals and super-oxide ions formed after the initial production of highly reactive electron and hole pairs when the photocatalysts are UV or visible-light irradiated (Augugliaro et al., 2006; Henderson, 2011).

The photocatalytic process over $\mathrm{TiO}_{2}$ requires a UV-light source, which exceeds the band-gap energy of $\mathrm{TiO}_{2}$, and the choice of the light source depends on economics as well as availability. In recent, lightemitting diodes(LEDs), as semiconductor light sources, have several advantages over those conventional light sources. LEDs are more efficient in converting electricity into light due to high quantum yields close to unity, thereby leading to low electricity consumption (Wikipedia, 2010). In addition, they have a long lifetime. As such, LEDs have been suggested as promising alternative light sources to conventional lamps for photocatalytic processes of environmental pollutants. Certain researchers(Chen et al., 2007; Shie et al., 2008) have suggested the feasibility of UV-LEDs used in the photocatalytic applications for the efficient removal of certain environmental pollutants. However, these previous studies applied $\mathrm{TiO}_{2} / \mathrm{UV}$-LED units for the photocatalytic degradation of an aqueous o-cresol(Chen et al., 2007) or of industrial emissionlevel(500 ppm) gaseous formaldehyde(Shie et al., 2008). Moreover, the gaseous formaldehyde level investigated by Shie et al.(2008) is substantially higher than typical indoor air quality(IAQ) levels(Jia et al., 2008; Pérez-Rial et al., 2010).

Extrapolation of photocatalysis performance data collected at concentrations much higher than those in the intended application are not likely valid( $\mathrm{Yu}$ and Brouwers, 2009). In addition, previous studies (Demeestere et al., 2005; Yu and Brouwers, 2009) emphasized that the kinetics and/or photocatalytic mechanism for gas-phase pollutant removals can vary with initial concentration levels. For gas-phase applications, photocatalytic reactors having high gas-feeding rates are preferred, since more air can be purified(Zhao and Yang, 2003). This suggests that an annular-type photocatalytic reactor is preferred for indoor air applications to a recirculating batch reactor used by Shie et al.(2008). Accordingly, the current study was designed to evaluate the applicability of UV-LED to annular-type photocatalytic reactor for removal of indoor-level benzene and toluene at a low concentration range $(<1 \mathrm{ppm})$ associated with IAQ issues. This type of reactor geometry requires a photocatalyst coating procedure with a thin film of the $\mathrm{TiO}_{2}$ photocatalyst onto the inner wall of reactor, which involves a baking process. Thus, this study also examined the potential effect of baking temperature applied for photocatalyst coating on photocatalytic activity.

\section{Methodology}

2.1. Experimental set-up and procedures

A schematic diagram of experimental set-up is 
presented in Fig. 1. Major experimental apparatuses included the pure air-supply system, humidification system, mixing chamber, and reactor. Dried air, which was supplied from a zero-grade air cylinder, was allowed to pass through a charcoal filter for re-purification. The re-purified air flowed into a humidification system and then, into a heated bulb to mix with standard compounds, which were injected via a syringe pump(Model 210, KdScientific Inc.), to generate a standard gas $(0.1 \mathrm{ppm})$. The relative humidity(RH) was fixed at 50-55\%, measuring just in front of the photocatalytic reactor inlet using a humidity meter(Thermo Recorder TR-72S, T \& D Co.). The gas flow rate was adjusted at a range of 0.1-0.5 L min ${ }^{-1}$. An annular-type reactor consisted of two Pyrex tubes with different diameters but with a same length. An hexahedral tube installed with UV-LED lamps was inserted inside the smallerdiameter Pyrex tube. The inner wall of the outer Pyrex tube was coated with a thin film of a commercially available Degussa $\mathrm{P}-25 \mathrm{TiO}_{2}$ powders (Japan Aerosil Inc.). The coated reactor is then dried for an hour at room temperature and baked at 350 , 450 , 550, or $650{ }^{\circ} \mathrm{C}$ for $30 \mathrm{~min}$. The reactor was designed to direct the flow of incoming air toward the UV light in order to increase the air turbulence inside the reactor, thereby enhancing the distribution of the target compounds onto the $\mathrm{TiO}_{2}$ surface. The UV radiation was supplied by two types of UV-LEDs (MS-L510UV365 \& MS-L510UV380, Moksan Electric Co.) with maximum spectral intensities at 365 and $380 \mathrm{~nm}$, respectively. The light intensities were adjusted at $2.4,2.5,3.1$, or $3.5 \mathrm{~mW} \mathrm{~cm}^{-2}$ by varying the supplied voltage. The coated $\mathrm{TiO}_{2}$ powders were characterized using an X-ray diffraction (XRD) meter operated at $40 \mathrm{kV}$ and 100 $\mathrm{mA}(\mathrm{D} / \mathrm{max}-2500$ diffractometer, Rigaku Inc.). In addition, the particle morphology was observed using a scanning electron microscope(SEM)(Hitachi S-4300\& EDX-350 FE-SEM) at an acceleration voltage of $15 \mathrm{kV}$.

The survey protocol included a procedure control program. After the reactor outlet humidity level reached equilibrium, the annular-type reactor was pretreated for several hours by flowing humidified

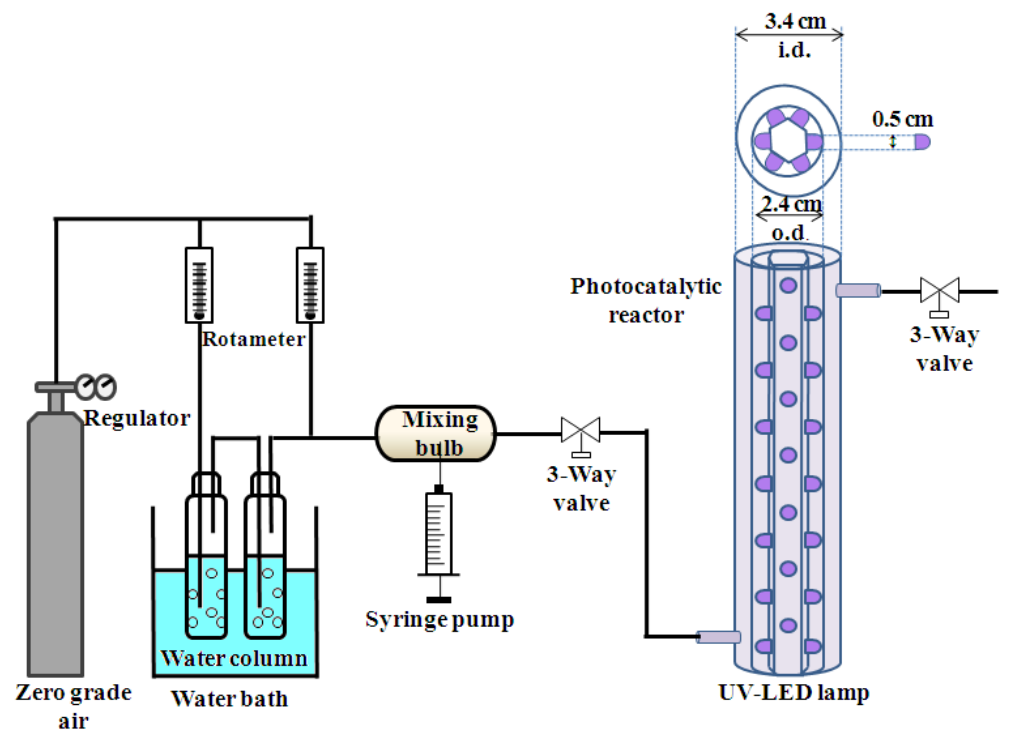

Fig. 1. Schematic diagram of experimental set-up. 
zero-grade air through the illuminated reactor. When no contamination with the target compounds was measured in the reactor, the benzene and toluene mixture was introduced. After the adsorption process between the titania catalyst and the target compounds reached an equilibrium, as indicated by equality between the inlet and outlet concentrations, the light source was turned on.

\subsection{Sampling and analysis}

Air samples over time were collected at the inlet and outlet of the photocatalytic unit prior to and after lamp activation. Prior to lamp activation, three 10-min samples were collected for $3 \mathrm{~h}$, at an interval of an hour. Adsorption equilibrium for the photocatalytic unit was observed over this time period. Then, the lamp was turned on, and air samples were collected for another $3 \mathrm{~h}$ at an interval of an hour. All samples were taken at ambient room temperatures $\left(19-25{ }^{\circ} \mathrm{C}\right)$. The gaseous compounds in the air stream were collected using a 0.64 -cm-outside diameter and 10-cm-long stainless steel sorbent trap containing $0.3 \mathrm{~g}$ of Tenax TA connected to a constant flow-sampling pump (Aircheck Sampler Model 224-PCXR8, SKC Inc.). The sampling times varied from 5 to 10 min depending on the flow rate.

The gaseous compounds collected on the Tenax TA trap were analyzed by coupling a thermal desorption system(TDS, ATD 400, Perkin Elmer Inc.) to a gas chromatograph(GC, 7890A, Agilent Inc.) with a flame ionization detector using a $0.32-\mathrm{mm}-\mathrm{i}$.d. by 60-m long fused silica column(DB-1, Alltech Inc.). The adsorbent trap was thermally desorbed at $250{ }^{\circ} \mathrm{C}$ for $10 \mathrm{~min}$, and the target compounds cryofocussed at $120{ }^{\circ} \mathrm{C}$ on a cryo trap(15.2-cm-long, 0.32-cm-o.d. tube packed with glass beads). The cold trap was rapidly heated to $250{ }^{\circ} \mathrm{C}$, then the contents were flushed into the Cryofocusing Module $(\mathrm{CM})$ of the TDS and cooled to $120{ }^{\circ} \mathrm{C}$ to refocus the target compounds. The $\mathrm{CM}$ was then heated to $225^{\circ} \mathrm{C}$ and flushed to transfer the target compounds to the GC. The initial oven temperature was set at $35{ }^{\circ} \mathrm{C}$ for five min and ramped at $4{ }^{\circ} \mathrm{C} \min ^{-1}$ to $200{ }^{\circ} \mathrm{C}$ for five min.

The quality control program included laboratory blank traps and spiked samples. At the beginning of the day, a laboratory blank trap was analyzed to check for any trap contamination; however, no trap contamination was identified. An external standard was also analyzed daily to check the quantitative response. The method detection limits were 0.2 and $0.1 \mathrm{ppb}$ for benzene and toluene, respectively.

\section{Results and discussion}

\subsection{Characterization of photocatalyst}

The morphological and optical properties of $\mathrm{TiO}_{2}$ powders used in the present study were obtained from XRD and SEM analyses. Figure 2 shows the XRD patterns of $\mathrm{TiO}_{2}$ powders. The X-ray diffractograms of this photocatalyst exhibited an anatase crystal phase with a distinct peak at $2 \theta=25.2^{\circ}$ and a rutile crystal phase with a distinct peak at $2 \theta=27.4^{\circ}$. This pattern is consistent with the results of previous studies (Zhang et al., 2006; Balzs et al., 2008). Accordingly, it is suggested that the photocatalyst used in the current study has photocatalytic activity when UV light is irradiated onto its surface.

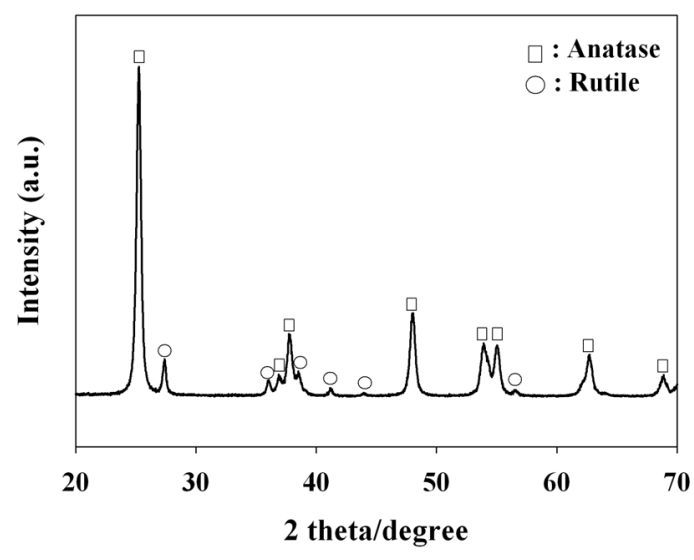

Fig. 2. X-ray diffraction spectra of $\mathrm{TiO}_{2}$ powders. 
Using the XRD patterns, the anatase content $\left(\mathrm{C}_{\mathrm{AT}}\right)$ in $\mathrm{TiO}_{2}$ powders were calculated using equation 1(Ohno et al., 2004):

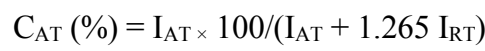

Where $I_{A T}$ and $I_{R T}$ represent peak intensities of anatase and rutile, respectively, obtained from XRD patterns. The $\mathrm{C}_{\mathrm{AT}}$ was estimated to be $89 \%$, indicating the rutile content to be $11 \%$. Additionally, the average crystallite diameters $\left(\mathrm{D}_{\mathrm{C}}\right)$ were calculated using equation 2 (Demeestere et al., 2005) on the anatase $\left(2 \theta=25.2^{\circ}\right)$ diffraction peak and the rutile $(2$ $\theta=27.4^{\circ}$ ) having the highest intensity:

$$
\mathrm{D}_{\mathrm{C}}=\mathrm{K} /(\cos \theta)
$$

Where $K(0.9)$ represents a shape factor for spherical particles, $\lambda(0.154 \mathrm{~nm})$ the wavelength of the incident radiation, $\theta$ half of the diffraction angle, and $\beta(B-b)$ the line broadening. $B$ is the full width at half maximum of the measured diffraction peak and $b(0.002)$ is the instrumental broadening. The average anatase crystallite diameter was $29 \mathrm{~nm}$, whereas the average rutile crystallite diameter was 58 $\mathrm{nm}$. This can only be considered as a first approximation, because of the narrow diffraction peaks observed. Rutile crystallite sizes were significantly larger than those of anatase, which is consisten with other studies(Mansilla et al., 2007; Balázs et al., 2008). From the XRD data point of view, the structural differences between the crystallites are marginal. Consistently, the SEM image revealed that the powder size is in the range of $20-80 \mathrm{~nm}$ (Fig. 3). Assuming that the samples constitute of uniform spheres, an average particle diameter of $2080 \mathrm{~nm}$ can be estimated, in good agreement with those derived from previous studies(Mansilla et al., 2007; Balázs et al., 2008; Zhao et al., 2011).

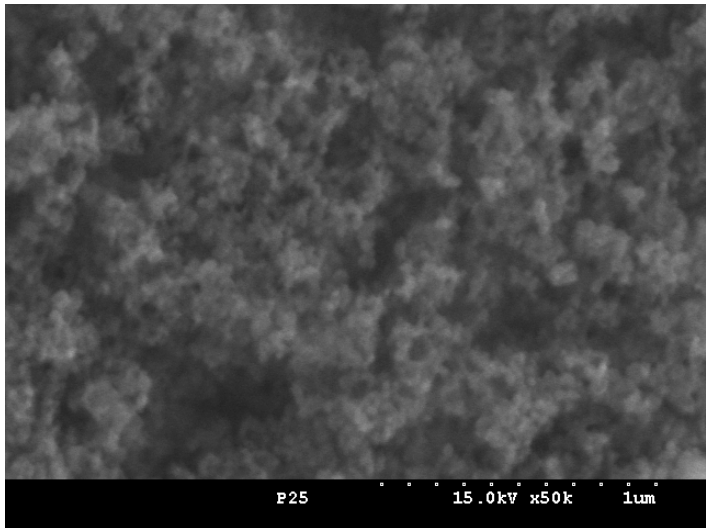

Fig. 3. Scanning electron microscopy images of $\mathrm{TiO}_{2}$.

\subsection{Photocatalytic activity dependence on baking} temperature

The effect of photocatalyst baking temperature applied for coating onto Pyrex tube on photocatalytic decomposition efficiency(PDE) of benzene and toluene was investigated. Fig. 4 represents the PDEs of the target compounds, as determined via $\mathrm{TiO}_{2}$ powders baked at four different temperatures. The $\mathrm{TiO}_{2}$ powders baked at $350{ }^{\circ} \mathrm{C}$ exhibited the highest PDEs for both benzene and toluene, and the photocatalysts baked at three higher temperatures $\left(450,550\right.$, and $\left.650{ }^{\circ} \mathrm{C}\right)$ did similar PDEs for these compounds. The average PDEs over a 3 -h period were $81 \%$ for benzene and close to $100 \%$ for toluene regarding the $\mathrm{TiO}_{2}$ powders baked at $350{ }^{\circ} \mathrm{C}$, whereas they were 61 and $74 \%$ for benzene and toluene, respectively, regarding the photocatalyst baked at 650 ${ }^{\circ} \mathrm{C}$. A similar result was reported by Nosaka et al.(2005) in that the photocatalytic activity of N-doped $\mathrm{TiO}_{2}$, which was determined from the formation of acetone, was highest for the photocatalyst calcined at $350{ }^{\circ} \mathrm{C}$ within a calcination temperature range of 350-550 ${ }^{\circ} \mathrm{C}$. However, another study(Znad and Kawase, 2009) reported that the decolorization rate of the Orange II has increased 6 times as the calcinations temperature of the S-doped $\mathrm{TiO}_{2}$ increased 
from 100 to $550{ }^{\circ} \mathrm{C}$. This was ascribed to gradual crystallization of the anatase $\mathrm{TiO}_{2}$ with temperature rising, while further increase in the calcinations temperature(to $700{ }^{\circ} \mathrm{C}$ ) resulted in an obvious decrease in the activity, which was ascribed to the increase of the crystalline size. Similarly, Yao et al.(2010) reported that aqueous phenol and methyl orange degradation increased notably with increasing calcination temperature of $\mathrm{TiO}_{2}$ from 300 to $500{ }^{\circ} \mathrm{C}$, while it decreased when the temperature is further raised to $600{ }^{\circ} \mathrm{C}$. This suggests that calcination temperature dependency of photocatalytic activity likely varies with operational conditions such as the type of photocatalyst and survey temperature range. Accordingly, the highest PDE obtained at the calcination temperature condition of $350{ }^{\circ} \mathrm{C}$ in the present study is likely due to a small size of crystalline powders having high specific area as determined using XRD data above.

3.3. Photocatalytic activity dependence on light intensity

The photocatalytic process over $\mathrm{TiO}_{2}$ occurs when a UV-light source, which exceeds the band-gap energy of $\mathrm{TiO}_{2}$, is irradiated onto the surface of the

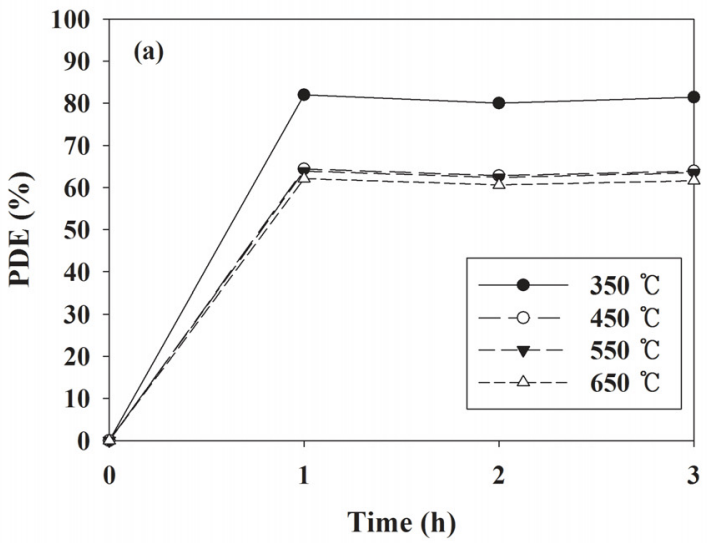

photocatalyst. Commonly, UV light with the wave length of near $300385 \mathrm{~nm}$ is used to provide energy to induce the process of the photo-sensation(Zhao and Yang, 2003). However, the activity of the photocatalyst depends strongly on the photon flux on the surface of the catalyst as well as the lightirradiation(energy per unit area), which is associated with wavelength. Accordingly, the present study investigated the photocatalytic activity dependence on light intensity. Figure 5 reveals the photocatalytic degradation efficiency of benzene and toluene as determined under the operational conditions of different light intensities. The differences in light intensities are attributed to the different power supplies. The PDES of both target compounds increased as the light intensity increased. As the light intensity increased from 2.4 to $3.5 \mathrm{MW} \mathrm{cm}^{-1}$, the average PDE obtained from the 3-h photocatalytic process increased from 36 to $81 \%$ and from $44 \%$ to close to $100 \%$ for benzene and toluene, respectively. Similarly, previous studies(Yang and Liu, 2007; Sekiguchi et al., 2010) reported that the oxidation rate of aromatic compounds or trichloroethylene decreased with an decrease in the UV intensity. However, only a part of the generated electronhole

Fig. 4. Photocatalytic degradation efficiency(PDE, \%) of (a) benzene and (b) toluene, as determined using $\mathrm{TiO}_{2}$ powders baked at four different temperatures $\left(350,450,550\right.$, and $\left.650{ }^{\circ} \mathrm{C}\right)$ applied for their coating onto Pyrex tube. 


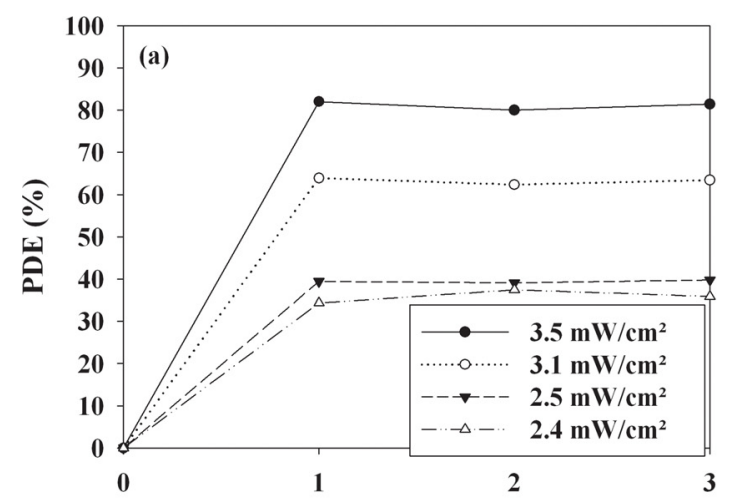

Time (h)

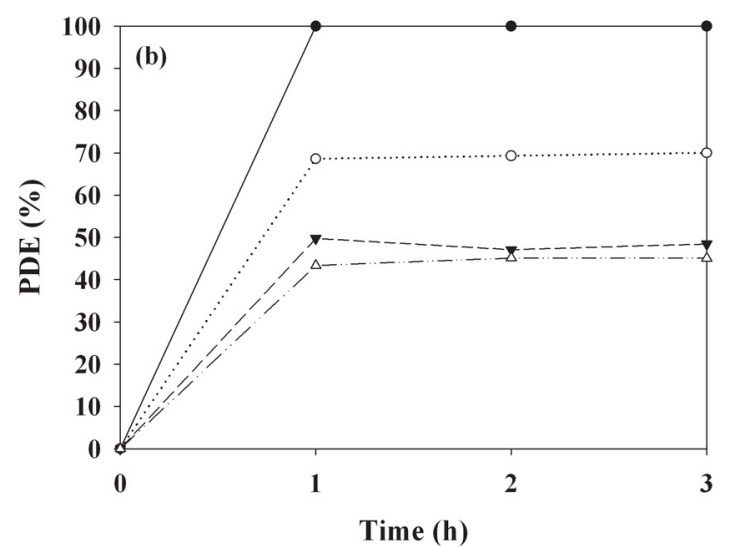

Time (h)

Fig. 5. Photocatalytic degradation efficiency(PDE, \%) of (a) benzene and (b) toluene according to light intensities(2.4, 2.5, 3.1 , and $3.5 \mathrm{~mW} \mathrm{~cm}^{-2}$ ).

pairs participates in chemical conversion reactions, whereas the other part undergoes recombination (Fujishima et al., 2007; Sakkas et al., 2010). This makes define two regimes as regards to the effect of light intensity on PDEs: 1) a first-order regime in which electronhole pairs are consumed more rapidly by chemical reactions than by recombination, that is, at low light intensity and high input concentration, and 2) a half-order regime in which recombination is the most dominant process, that is, at high light intensity and low input concentration. At even higher light intensities, PDE becomes independent of light intensity and the reaction rate becomes mass transfer limited(Liu and Zhao, 2010; Sekiguchi et al., 2010). As such, it is suggested that the photocatalytic activity dependence on light intensity obtained in the present study belongs the first-order regime. A further suggestion is that there is an optimal light intensity for the photocatalytic process using a $\mathrm{TiO}_{2} / \mathrm{UV}$-LED system.

\subsection{Photocatalytic activity dependence on flow rate}

Figure 6 represents the PDEs of BTEX, as determined at four different FRs. The PDEs of all target compounds decreased as the FR increased. As the FR increased from 0.1 to $0.5 \mathrm{~L} \mathrm{~min}^{-1}$, the average PDE obtained from the 3-h photocatalytic process decreased from $81 \%$ to close to zero and from close to $100 \%$ to $7 \%$ for benzene and toluene, respectively. The lower degradation efficiencies for the target compounds at the high flow rates are most likely due to an insufficient reactor residence time for these pollutants to transfer from the gas phase to the catalyst surface. This assertion is supported by finding that the residence times in the present study, which were calculated by dividing the reactor volume by the flow rate, were $2.4,1.2,0.6,0.3$, and $0.15 \mathrm{sec}$ and $13.2 \mathrm{sec}$ for flow rates of $0.1,0.2,0.3,0.4$, and $0.5 \mathrm{~L} \mathrm{~min}^{-1}$ respectively. However, face velocity, calculated by dividing volumetric flow rate by cross-sectional area of photocatalytic reactor, decreases as RT increases. The mass transfer of bulk VOCs to the surface of photocatalyst, which is closely associated with face velocity, is an important parameter which affects PDEs(Van Gerven et al., 2007; Yang et al., 2007). In a low face velocity regime, the mass transfer increased as the face velocity increased, thereby elevating photocatalytic reaction rates(Van Gerven et al., 2007). In contrast, the PDEs obtained from the present study decreased as the face velocities increased. As such, the lower 

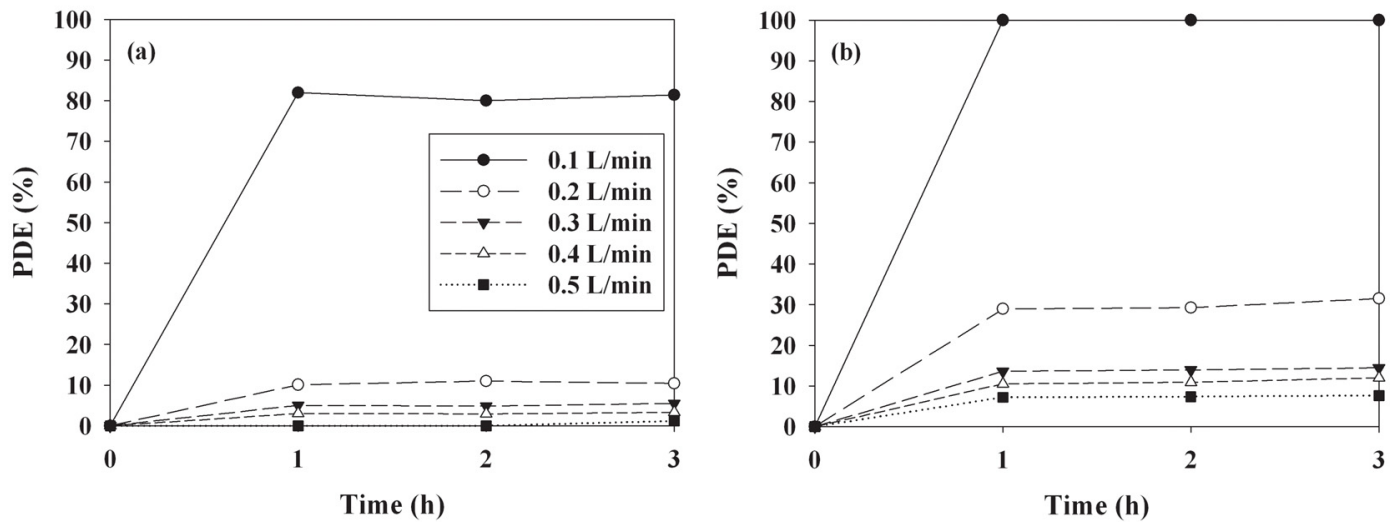

Fig. 6. Photocatalytic degradation efficiency(PDE, \%) of (a) benzene and (b) toluene according to flow rates $(0.1,0.2,0.3$, 0.4 , and $0.5 \mathrm{~L} \mathrm{~min}^{-1}$ ).

PDEs of benzene and toluene for shorter RTs (higher face velocities) are attributed to an insufficient reactor reaction time for the photocatalysis of these compounds, rather than the mass transfer effect.

In addition, the photocatalytic oxidation rates were calculated by using the following equation:

$$
r=k\left(C_{i} C_{o}\right) Q / A
$$

where $C_{i}$ and $C_{o}$ represent the inlet and outlet benzene or toluene concentrations(ppm), respectively; $Q$ represents the volumetric flow $\operatorname{rate}\left(\mathrm{m}^{3} \mathrm{~s}^{-1}\right) ; A$ represents the photocatalyst-coated area $\left(\mathrm{m}^{2}\right)$; and $k$ represents the conversion factor(40.9 -mole $\mathrm{m}^{-3}$ $\mathrm{ppm}^{-1}$ ). The reaction rate decreased as the FR increased for both benzene and toluene(Table 1). This pattern supports that PDEs decreased as FR increased.

\section{Conclusions}

This study investigated the applicability of UV-LED to annular-type photocatalytic reactor for removal of indoor-level benzene and toluene at a low concentration range associated with IAQ issues. It was found that the annular-type photocatalytic reactor inner-inserted with UV-LEDs can effectively be applied for the decomposition of low-level benzene and toluene. The photocatalytic performance of this reactor was supported by the photocatalytic activity test as well as the morphological and optical properties of the photocatalysts. Another major finding is that three parameters(baking temperature for photocatalyst coating onto reactor, light intensity, and FR) should also be considered for better VOC removal efficiencies when applying the annular-type photocatalytic reactor inner-inserted with UV-LEDs to clean lowlevel indoor VOCs. Nevertheless, it is suggested that conventional lamps are preferable when a high removal efficiency of benzene is required, due to higher PD performance of the conventional lamp/ photocatalytic systems compared to that of the

Table 1. Reaction rate $\left(\mu-m o l e ~ \mathrm{~m}^{-2} \mathrm{~s}^{-1}\right)$ of benzene and toluene according to flow rate

\begin{tabular}{cccccc}
\hline \multirow{2}{*}{ Compound } & \multicolumn{5}{c}{ Flow rate $\left(\mathrm{L} \mathrm{min}^{-1}\right)$} \\
\cline { 2 - 6 } & 0.1 & 0.2 & 0.3 & 0.4 & 0.5 \\
\hline \hline Benzene & $1.7 \times 10^{-3}$ & $4.2 \times 10^{-4}$ & $3.1 \times 10^{-4}$ & $2.5 \times 10^{-4}$ & $1.0 \times 10^{-4}$ \\
Toluene & $2.1 \times 10^{-3}$ & $1.2 \times 10^{-3}$ & $8.7 \times 10^{-4}$ & $8.3 \times 10^{-4}$ & $7.2 \times 10^{-4}$ \\
\hline
\end{tabular}


LED/photocatalytic systems.

\section{Acknowledgements}

This work was supported by the National Research Foundation of Korea(NRF) grant funded by the Korea government (MEST) (2011-0027916).

\section{Reference}

Aïssa, A. H., Puzenat, E., Plassais, A., Herrmann, J. -M., Haehnel, C., Guillard, C., 2011, Characterization and photocatalytic performance in air of cementitious materials containing $\mathrm{TiO}_{2}$. Case study of formaldehyde removal, Appl. Catal. B, $107,1-8$.

Augugliaro, V., Litter, M., Palmisano, L., Soria, J., 2006, The combination of heterogeneous photocatalysis with chemical and physical operations: a tool for improving the photoprocess performance, J. Photochem. Photobiol. C, 7, 127-144.

Balázs, N., Mogyorósi, K., Srankó, D. F., Pallagi, A., Alapi, T., Oszkó, A., Dombi, A., Sipos, P., 2008, The effect of particle shape on the activity of nanocrystalline $\mathrm{TiO}_{2}$ photocatalysts in phenol decomposition, Appl. Catal. B, 84, 356-362.

Boughelouma, C., Messalhi, A., 2009,. Photocatalytic degradation of benzene derivatives on $\mathrm{TiO}_{2}$ catalyst, Phys. Proc., 2, 1055-1058.

Chen, H. W., Ku, Y., Irawan, A., 2007, Photodecomposition of o-cresol by UV LED/TiO 2 process with controlled periodic illumination, Chemosphere, 69, 184-190.

Choi, H., Stathatos, E., Dionysiou, D. D., 2007, Photocatalytic $\mathrm{TiO}_{2}$ films and membranes for the development of efficient wastewater treatment and reuse systems, Desalination, 202, 199-206.

Demeestere, K., Dewulf, J., Ohno, T., Salgado, P. H., Van Langenhove, H., 2005, Visible light mediated photocatalytic degradation of gaseous trichloroethylene and dimethyl sulfide on modified titanium dioxide, Appl. Catal. B, 61, 140-149.

Fujishima, A., Zhang, X., Tryk, D. A., 2007, Heterogeneous photocatalysis: Fromwater photolysis to applications in environmental cleanup, Int. J. Hydrogen Ener., 32, 2664-2672.

Häninen, O. O., Lebret, E., Ilacqua, V., Katsouyanni, K., Künzli, N., Srám, M., Jantunen, M., 2004, Infiltration of ambient PM2.5 and levels of indoor generated non-ETS in residences of four European cities, Atmos. Environ., 38, 64116423.

Henderson, M. A., 2011, A surface science perspective on $\mathrm{TiO}_{2}$ photocatalysis, Surf. Sci. Rep. 66, 185-297.

IARC(International Agency for Research on Cancer), 2004, Monographs on the evaluation of the carcinogenic risks of chemicals to man, WHO, Geneva.

Jia, C., Batterman, S., Godwin, C., 2008, VOCs in industrial, urban and suburban neighborhoods Part 2: factors affecting indoor and outdoor concentrations, Atmos. Environ., 42, 2101-2116.

Liu, B., Zhao, X., 2010, A kinetic model for evaluating the dependence of the quantum yield of nano- $\mathrm{TiO}_{2}$ based photocatalysis on light intensity, grain size, carrier lifetime, and minority carrier diffusion coefficient: Indirect interfacial charge transfer, Electrochim. Acta, 55, 4062-4070.

Lu, C. -Y., Wey, M. -Y., 2007, Simultaneous removal of VOC and NO by activated carbon impregnated with transition metal catalysts in combustion flue gas, Fuel Proc. Technol., 88, 557-567.

Mansilla, H. D., Mora, A., Pincheira, C., Mondaca, M. A., Marcato, P. D., Durán, N., Freer, J., 2007, New photocatalytic reactor with $\mathrm{TiO}_{2}$ coating on sintered glass cylinders, Appl. Catal. B 76, 57-63.

Nosaka, Y., Matsushita, M., Nishino, J., Nosaka, A. Y., 2005, Nitrogen-doped titanium dioxide photocatalysts for visible reponse prepared by using organic compounds, Sci. Technol. Adv. Mater., 6, 143-148.

Ohno, T., Akiyoshi, M., Umebayashi, T., Asai, K., Mitsui, T., Matsumura, M., 2004, Preparation of S-doped $\mathrm{TiO}_{2}$ photocatalysts and their photocatalytic activities under visible light, Appl. Catal. 265, 115-121.

Ohura, T., Amagai, T., Shen, X., Li, S., Zhang, P., Zhu, L., 2009, Comparative study on indoor air quality in Japan and China: characteristics of residential 
indoor and outdoor VOCs, Atmos. Environ., 43, 6352-6359.

Pérez-Rial, D., López-Mahía, P., Tauler, R., 2010, Investigation of the source composition and temporal distribution of volatile organic compounds (VOCs) in a suburban area of the northwest of Spain using chemometric methods, Atmos. Environ., 44, 5122-5132.

Revilla, A. S., Pestana, C. R., Pardo-Andreu, G. L., Santos, A. C., Uyemura, S. A., Gonzales, M. E., Curti, C., 2007, Potential toxicity of toluene and xylene evoked by mitochondrial uncoupling, Toxicol.Vitro, 21, 782-788.

Roukos, J., Riffault, V., Locoge, N., Plaisance, H., 2009, $\mathrm{VOC}$ in an urban and industrial harbor on the French North Sea coast during two contrasted meteorological situations, Environ. Poll., 157, 3001-3009.

Sakkas, V. A., Islam, M. A., Stalikas, C., Albanis, T. A., 2010, Photocatalytic degradation using design of experiments: A review and example of the Congo red degradation, J. Hazard. Mater., 175, 33-44.

Schlink, U., Thiem, A., Kohajda, T., Richter, M., Strebel, K., 2010, Quantile regression of indoor air concentrations of volatile organic compounds (VOC), Sci. Total Environ., 408, 3840-3851.

Sekiguchi, K., Morinaga, W., Sakamoto, K., Tamura, H., Yasui, F., Mehrjouei, M., Mller, S., Mller, D., 2010, Degradation of VOC gases in liquid phase by photocatalysis at the bubble Interface, Appl. Catal. B, 97, 190-197.

Shie, J. L., Lee, C. H., Chiou, C. S., Chang, C. T., Chang, C. C., Chang, C. Y., 2008, Photodegaradation kinetics of formaldehyde using light sources of UVA, UVC and UVLED in the presence of composed silver titanium oxide photocatalyst, J. Hazard. Mater., 155, 164-172.

Van Gerven, T., Mul, G., Moulijn, J., Stankiewicz, A., 2007, A review of intensification of photocatalytic processes, Chem. Eng. Prog., 46, 781-789.

Yang, L., Liu, Z., 2007, Study on light intensity in the process of photocatalytic degradation of indoor gaseous formaldehyde for saving energy, Ener. Conv. Manage., 48, 882-889.

Yang, L., Liu, Z., Shi, J., Hu, H., Shangguan, W., 2007, Design consideration of photocatalytic oxidation reactors using $\mathrm{TiO}_{2}$-coated foam nickels for degrading indoor gaseous formaldehyde, Catal. Today, 126, 359-368.

Yu, Q. L., Brouwers, H. J. H., 2009, Indoor air purification using heterogeneous photocatalytic oxidation. part I: experimental study, Appl. Catal. B, 92, 454-461.

Zhang, G., Gong, J., Zou, X., He, F., Zhang, H., Zhang, Q., Liu, Y., Yang, X., Hu, B., 2006, Photocatalytic degradation of azo dye acid red $\mathrm{G}$ by $\mathrm{KNb}_{3} \mathrm{O}_{8}$ and the role of potassium in the photocatalysis, Chem. Eng. J., 123, 59-64.

Zhao, J., Yang, X., 2003, Photocatalytic oxidation for indoor air purification: a literature review, Build. Environ., 38, 645-654.

Zhao, J., Wan, P., Xiang, J., Tong, T., Dong, L., Gao, Z., Shen, X., Tong, H., 2011, Synthesis of highly ordered macro-mesoporous anatase $\mathrm{TiO}_{2}$ film with high photocatalytic activity, Micropor. Mesopor Mater., 138, 200-206.

Znad, H., Kawase, Y., 2009, Synthesis and characterization of S-doped Degussa P25 with application in decolorization of Orange II dye as a model substrate, J. Mole. Catal. A, 314, 55-62. 